\title{
Effects of Cardiopulmonary Bypass Temperature and Time on Inflammatory Response
}

\author{
Ese H.Caran Karaoglu \\ Bursa High Specialist Education and Research Hospital, Bursa, Turkey \\ E-mail: esehkaraoglu@gmail.com \\ Harun Karaoglu \\ Bursa High Specialist Education and Research Hospital, Bursa, Turkey \\ E-mail: harunkaraoglu@yandex.com \\ Cenk Eray Yildiz \\ Istanbul University Cerrahpasa Cardiology Institute, Cardiovascular Surgery, Istanbul, Turkey \\ E-mail: ceyildiz@hotmail.com
}

Bu çalı̧̧a, İstanbul Üniversitesi Bilimsel Araştırma Projeleri Birimi tarafindan desteklenmişstir. Proje No: 25789

\begin{abstract}
Background: To investigate the effect of cardiopulmonary bypass temperature and duration on inflammatory response in patients undergoing open heart surgery.

Methods: The study group consisted of 43 patients and the patients were divided into two groups. Group 1 (n: 17) was operated using hypothermic bypass and group 2 (n: 26) was operated using normothermic bypass. Blood samples were taken for CRP, IL-6, IL-10 and TNF- $\alpha$ levels in the preoperative and postoperative period.

Results: The demographic and preoperative characteristics of the patients were similar. The CRP level was significantly higher in the normothermic group than in the hypothermic group (Group 1: $92.2 \pm 36.36$, Group2: $120.58 \pm 47.55)(\mathrm{p}<0.05)$. In both groups, TNF- $\alpha$, IL-6 and IL- No statistically significant difference was found in 10 values. ( $p>0.05$ ) When we evaluated the effect of CPB duration on inflammatory response, one unit change in aortic cross clamp duration increased IL-10 by 0.175 fold ( $p=$ $0.042<0.05$ ). The operation time was $10 \%$ significant. It was observed that 1 unit increase in the duration of operation increased the IL-6 level by 0.203 fold. ( $\mathrm{P}<0.05)$

Conclusion: According to these results, it was seen that there was no significant difference in normothermic and hypothermic CPB patients, but prolonged operation time and aortic cross clamp duration increased inflammatory response.
\end{abstract}

Key words: Cardiopulmonary bypass, hypothermia, inflammatory response, cytokine, open heart surgery

DOI: $10.7176 / \mathrm{JSTR} / 5-2-35$

\section{Kardiyopulmoner Baypas Isısının ve Süresinin İnflamatuvar Yanıt Üzerine Etkileri}

ÖZET

Amaç: Açık kalp cerrahisi uygulanan hastalarda kardiyopulmoner baypas ısısı ve süresinin inflamatuvar yanıt üzerine etkisinin araştırılması.

Yöntemler: Çalışmaya 43 hasta alınmış olup, hastalariki gruba ayrıldı. Grup 1 (n:17) hipotermik baypaskullanılarak opere edilmiş, grup 2 (n:26) normotermik baypaskullanılarak opere edilmiştir. 
Hastalardan preoperatif ve postoperatif dönemde CRP, IL-6, IL-10 ve TNF- $\alpha$ düzeyleri için kan örnekleri alınmıştır.

Bulgular: Hastaların demografik ve preoperatif özellikleri benzerdi. CRP değeri normotermik grupta hipotermik gruba göre anlamlı yüksek bulunmuştur. (Grup1: 92,2 $\pm 36,36$, Grup2: 120,58 $\pm 47,55)(\mathrm{p}<0.05)$ Her iki grupta TNF- $\alpha$, IL-6 ve IL-10 değerlerinde istatistiksel olarak anlamlı farklılık bulunmamıştır. $(\mathrm{p}>0.05)$ KPB süresinin inflamatuvar yanıta etkisini hasta bazındadeğerlendirdiğimizde, aorta kros klemp süresindeki bir birimlik değişim IL-10'u 0,175 kat arttırdığg 1 görülmüştür $(p=0,042<0,05)$. Operasyon süresi \%10 anlamlı bulunmuştur. Operasyon süresindeki 1 birimlik değişimin IL-6 düzeyini 0.203 kat artırdığı izlenmiştir. $(\mathrm{p}<0.05)$

Sonuç: Bu sonuçlara göre normotermik ve hipotermik KPB uygulanan hastalarda anlamlı farklılığın görülmediği fakat uzamış operasyon süresi ve aorta kros klemp süresinin inflamatuvar yanıtı arttırdığı görülmüştür.

Anahtar kelimeler: Kardiyopulmoner baypas, hipotermi, inflamatuvar yanıt, sitokin, açık kalp cerrahisi

\section{Giriş}

Koroner arter cerrahisinde kullanılan kardiyopulmoner baypas nedeniyle multifaktöriyel olarak indüklenen inflamatuvar cevap, postoperatif dönemde görülen morbidite ve mortalite ile doğrudan ilişkilidir. Kardiyopulmoner baypas'ın inflamatuvar mediyatörleri indüklemesi bir çok yolaktan gerçekleşebilir. Kompleman sistemi, sitokinler, koagülason-fibrinoliz kaskad1, endotel ve hücresel immün sistem bu mediyatörlerin oluşmasında etkilidir. Kardiyopulmoner baypas esnasında kan elemanlarının KPB sisteminin iç yüzeyi ile teması, iskemi/reperfüzyon hasarı(I/R), hipotermi, endotoksemi, cerrahi stres ve anestezi SIRS tablosunun oluşmasının nedenleri arasındadır(1,2). Bu çalışmada inflamatuvar yanıtın oluşmasında perfüzyon 1sısı ve süresinin rolünün belirlenmesi için bazı belirteçler ölçülmüştür.

CRP, en önemli akut faz reaktanlarındandır ve inflamatuvar süreçler sırasında dramatik bir şekilde yükselmektedir. Fizyolojik rolü, kompleks ile fosfokline bağlanarak kompleman sistemini aktive etmektir. IL-6, iskemi reperfüzyon hasarında da önemli rol oynayan çok fonksiyonlu bir proinflamatuvar sitokindir $(3,4)$. TNF- $\alpha$ kanda ilk yükselen sitokindir. KPB süresi ve proinflamatuvar sitokin seviyesi arasında önemli bir ilişki vardır (5).

Çoklu organ yetmezliğinde proinflamatuvar faktörlerin salınımı önemli bir etkendir. Bunların aksine KPB sırasında salınan IL-10 gibi antiinflamatuvar faktörler ise proinflamatuvar sitokinleri baskılar. Bu ikisi arasındaki denge klinik seyirde önemli etkendir. Ayrıca IL-10 kan mononükleer hücreleri ve konnektif doku hücreleri üzerinde de düzenleyici etki göstermektedir.

Hipotermik KPB`de, homeostatik mekanizmaların, hormon düzeylerinin ve organ perfüzyonunun iyi tolere edildiği gözlemlenmiştir. Normotermik KPB için araştırmalar devam etmektedir. Bu çalışmanın amacı, açık kalp cerrahisi sırasında sıcaklık ve sürenin inflamatuvar yanıt üzerine olan etkilerini değerlendirmektir.

\section{Yöntem}

2.1. Hasta grupları: Prospektif randomizekontrollü çalışmada hastalar, Bağcılar Eğitim ve Araştırma Hastanesi Kalp ve Damar Cerrahisi Anabilim Dalı’nda hipotermik ve normotermik KPB kullanılarak opere edilmiştir.Hipotermik grupta 17 hasta (yaş ortalamas159,23 $\pm 5,54$ ), normotermik grupta 26 (yaş ortalaması $52,24 \pm 12,8$ ) hasta çalışmaya alındı. Çalışmaya girmeyi reddeden, ejeksiyon fraksiyonu $<\% 35$, daha önceden geçirilmiş toraks cerrahisi ve kalp cerrahisi olan, sistemik inflamatuvar hastalık hikayesi bulunan, karaciğer enzimleri yüksek olan, daha önceden geçirilmiş serebrovasküler olay ve/veya nörolojik sekeli olan, bilinen organ yetmezliği (hepatik, renal, serebral) bulunan, geçirilmiş enfeksiyon hikayesi bulunan, daha önce kalp ameliyatı geçirmiş, daha önce kapak operasyonu öyküsü olan, C-reaktif protein $>5 \mathrm{mg} / \mathrm{dl}$, kreatinin değeri $>0.9 \mathrm{mg} / \mathrm{dl}$ olan hastalar çalışma dışı bırakılmıştır.

2.2. Operasyon Teknikleri: Median sternotomi ve heparinizasyon sonrası kanülayon yapıldı. Kardiyopulmoner baypasta Sorin İnspire (LivaNova PLC-Registereted in England and Wales) oksijenatör kullanıldı. Aorta antegrad kardiyopleji kanülü yerleştirildi. Kalp yükssek potasyum içerikli (30 mmol/L) solüsyon ile antegrad kardiyopleji verildi. Grup $1 \mathrm{KPB}^{\prime} \mathrm{de} 34^{\circ} \mathrm{C}<1$ sıya kadar soğutuldu. Grup 2 ise $\mathrm{KPB}$ $\geq 34^{\circ} \mathrm{C}$ ye 1 sıya kadar soğutuldu. Ortalama arter basınc $45-60 \mathrm{mmHg}$ arasında olacak şekilde gerekli müdahaleler yapıldı.operasyon sonrası heparin protamin hidroklorid ile nötralize edildi (Protamin 1000; Roche, Istanbul, Turkey). Dekanülasyon yapıldı. 
2.3. Örnek toplanmast: Hastalara santral venöz katater takılmasından sonra ilk kan örnekleri alındı. Daha sonra hasta KPB 'ye girdikten sonra aorta kros klemp konulduktan sonra 5. dk da ikinci kan örneği alındı. KPB 'den çıktıktan sonra 10. Dk da üçünü kan örneği alındı ve hasta yoğun bakıma alındıktan 24 saat sonra dördüncü kan örnekleri alındı. Alınan kan örnekleri laboratuvarda 3000 devirde 5 dk santrifüj edilerek plazmalar ayrılmış ve numuneler -40 derecede saklanmıştır.

IL-6 IL-10, TNF-alfa düzey ölçümlerinde enzyme-linked immunosorbent assay (ELİSA) yöntemi kullanıldı.(Human IL-6 Elısa Kit, Human IL-10 Elısa Kıt, Human TNF-alpha Elısa Kit).

2.4. İstatistiksel analiz: Sürekli değişkenleri tanımlamak için deskriptif istatistikler kullanılmıştır. (ortalama, standart sapma, minimum, medyan, maksimum)

Bağımsız ve normal dağılıma uygunluk göstermeyen iki değişkenin karşılaştırması Mann Whitney U testi ile yapılmıştır. Normal dağılıma uygunluk gösteren değişkenler için Bağımsız örneklem testi kullanılmıştır.

Kategorik değişkenler arası ilişkiler için Ki-Kare analizi kullanılmış uygun durumlarda Yates düzeltmesi yapilmıştır.

İstatistiksel anlamlılık düzeyi 0,05 olarak belirlenmiştir. Analizler MedCalc Statistical Software version 12.7.7 (MedCalc Software bvba, Ostend, Belgium; http://www.medcalc.org; 2013) Programı kullanılarak gerçekleştirilmiştir.

\section{Bulgular}

Grupların demografik özellikleri ve preoperatif özellikleri yönünden anlamlı farklılık bulunmadı ( $>>0.05)$. Her iki grupta operasyon süresi benzer bulunmuştur. (grup1:106.31 dk, grup2:83.59 dk). (p>0.05) Her iki grupta aorta kros klemp süreleri ve pompa süreleri (grup1:61.42 dk, grup2:49.59 dk) benzer bulunmuştur( $\mathrm{p}>0.05)$.(Tablo 1)

İndüksiyon öncesi alınan örneklerde IL-6 seviyelerinde anlamlı farklılık bulunmamıştır. (p>0.05) KPB sonrası alınan IL-6 seviyelerinde hipotermik grupta anlamlı olarak artmıştır. (Grup1: 54,43 $\pm 45,4$, Grup2:31,55 $\pm 16,05)$ Postop 24. saatte alınan örnekte IL-6 düzeyi normotermik grupta daha fazla yükselmesine rağmen istatistiksel olarak anlamlı bulunmamıştır( $\mathrm{p}>0.05)$.

Tablo 1. Hastaların intraoperatif özellikleri

\begin{tabular}{|c|c|c|c|c|}
\hline & Hipotermik & Normotermik & & \\
\hline & $\begin{array}{c}\text { Ort.+SS } \\
\text { Med. (Min.-Maks.) }\end{array}$ & $\begin{array}{c}\text { Ort.+SS } \\
\text { Med. (Min.-Maks.) }\end{array}$ & $p$ & $\mathrm{p}$ value \\
\hline Yaş & $\begin{array}{l}59,23 \pm 5,54 \\
61-(47-65)\end{array}$ & $\begin{array}{l}52,24 \pm 12,8 \\
54-(19-65)\end{array}$ & $0,061 * *$ & $\mathrm{p}>0.05$ \\
\hline ACT & $\begin{array}{c}562,5 \pm 79,94 \\
549-(400-740)\end{array}$ & $\begin{array}{l}578,53 \pm 105,82 \\
540-(460-891)\end{array}$ & $0,891 * *$ & $\mathrm{p}>0.05$ \\
\hline Operasyon_süresi (dk) & $\begin{array}{c}286,73 \pm 55,1 \\
285-(150-385)\end{array}$ & $\begin{array}{c}274,71 \pm 36,97 \\
270-(220-360) \\
\end{array}$ & $0,434^{*}$ & $\mathrm{p}>0.05$ \\
\hline Pompa_Süresi & $\begin{array}{c}106,31 \pm 44,93 \\
94-(56-256)\end{array}$ & $\begin{array}{l}83,59 \pm 33,72 \\
69-(45-158)\end{array}$ & $0,082 * *$ & $\mathrm{p}>0.05$ \\
\hline Aort_x_Klemp & $\begin{array}{c}61,42 \pm 29,57 \\
50,5-(33-145)\end{array}$ & $\begin{array}{l}49,59 \pm 27,85 \\
35-(22-130)\end{array}$ & $0,089 * *$ & $\mathrm{p}>0.05$ \\
\hline
\end{tabular}

Her iki grupta da AKK konulduktan sonra IL-6 yükselmeye başlamış ve post-op 24. saatte en yüksek değerine ulaşmıştır. Normotermik grupta postoperatif 24. saattte anlamlı yükselmiştir. $(\mathrm{p}<0.05)($ Tablo 2$)$ 
Tablo 2. IL-6 seviyeleri

\begin{tabular}{|l|c|c|c|}
\hline & Hipotermik & Normotermik & p value \\
\hline T1(indüksiyon öncesi) & $\begin{array}{c}3 \pm 1,75 \\
2,99-(0,06-7,93)\end{array}$ & $\begin{array}{c}4,52 \pm 3,19 \\
3,84-(0,09-14,22)\end{array}$ & $\mathrm{p}>0.05$ \\
\hline T2(AKK 5.dk) & $9,6 \pm 29,5$ & $7,1 \pm 5,84$ & $\mathrm{p}>0.05$ \\
\hline T3(KPB sonras1 10.dk) & $3,11-(0,06-153,19)$ & $6-(0,07-18,26)$ & $\mathrm{P}<0.05$ \\
\hline T4(postop 24. saat) & $54,43 \pm 45,4$ & $31,55 \pm 16,05$ & $\mathrm{p}>0.05$ \\
\hline
\end{tabular}

Her iki grupta alınan TNF- $\alpha$ seviyelerinde anlamlı farklılık bulunmamıştır.(Grup 1:1,45 $\pm 2,51$, Grup $2: 1,52 \pm 1,76)$ (Tablo3)

Tablo 3. TNF- $\alpha$ seviyeleri

\begin{tabular}{|l|c|c|c|}
\hline & Hipotermik & Normotermik & p value \\
\hline T2(AKK 5.dk) & $1,52 \pm 1,76$ & $1,45 \pm 2,51$ & $\mathrm{p}>0.05$ \\
\hline T4(Postop 24. saat) & $1,41 \pm 1,68$ & $1,23 \pm 2,37$ & $\mathrm{p}>0.05$ \\
\hline
\end{tabular}

CRP kardiyovasküler hastalıklar açısından bir risk göstergesi olabileceğinden operasyon sırası ve sonrasında düzeyinin ölçülmesi gelişebilecek komplikasyonların habercisi olabilir.

Grup 1 ve 2 'de bulunan hastaların preoperatif dönemde alınan kan örneklerinde anlamlı farklılık bulunmamıştır. (Tablo 4) Postoperatif CRP değerleri karşılaştırıldı̆̆ında ise preoperatif değerleri ile postoperatif 24. saatte bulunan değerlerin anlamlı derecede farklı olduğu görülmüştür. Ayrıca postop 24. Saatte alınan örneklerde normotermik grubun CRP değeri hipotermik gruba göre daha yüksek bulunmuştur. $(\mathrm{p}<0.05)$ (Tablo 4$)$

Tablo 4. CRP seviyeleri

\begin{tabular}{|l|c|c|c|}
\hline & Hipotermik & Normotermik & p value \\
\hline \multirow{2}{*}{ T1(indüksiyon öncesi) } & $9,68 \pm 10,11$ & $13,26 \pm 15,7$ & \\
& $6,05-(1,4-44)$ & $8,3-(0,4-49,3)$ & $\mathrm{p}>0.05$ \\
\hline \multirow{2}{*}{ T2(AKK 5.dk) } & $6,26 \pm 7,38$ & $7,61 \pm 9,31$ & $\mathrm{p}>0.05$ \\
\hline \multirow{2}{*}{ T3(KPB sonras1 10.dk) } & $3,15-(0,7-29,1)$ & $4,2-(0,5-28,2)$ & $\mathrm{p}>0.05$ \\
\hline \multirow{2}{*}{ T4(Postop 24. saat) } & $8,07 \pm 8,96$ & $13,43 \pm 20,52$ & $\mathrm{p}<0.05$ \\
& $90,25-(29,6-34,6)$ & $5,1-(0,5-81)$ & \\
\hline
\end{tabular}

Çalışmaya alınan her iki grupta IL-10 seviyesi preoperatif dönemde benzerdi. ( $\mathrm{p}>0.05) \mathrm{KPB}$ süresince benzer şekilde devam etmiştir. Aorta kros klemp sonrası alınan örneklerde her iki grupta anlamlı olarak yükselmeye başlamıştır. KPB sonrası pik noktasına ulaşmış ve 24. saatte düşmeye başlamıştır. 
Tablo 5 . IL-10 seviyeleri

\begin{tabular}{|l|c|c|c|}
\hline & Hipotermik & Normotermik & p value \\
\hline T1(indüksiyon sonras1) & $\begin{array}{c}3,43 \pm 2,44 \\
3,47-(0,01-7,63)\end{array}$ & $\begin{array}{c}8,09 \pm 9,51 \\
4,58-(0,72-40,15)\end{array}$ & $\mathrm{p}>0.05$ \\
\hline T2(AKK 5.dk) & $\begin{array}{c}29,05 \pm 88,04 \\
6,77-(0,02-449,46)\end{array}$ & $\begin{array}{c}11,1 \pm 10,49 \\
6,72-(1,54-46,31)\end{array}$ & $\mathrm{p}>0.05$ \\
\hline T3(KPB sonras1 10.dk) & $\begin{array}{c}501,04 \pm 261,58 \\
463,48-(3,72-1065,02)\end{array}$ & $\begin{array}{c}632,3-(204,911267,02) \\
532,31\end{array}$ & $\mathrm{p}>0.05$ \\
\hline T4(Postop 24. saat) & $\begin{array}{c}67,28 \pm 197,21 \\
14,26-(5,22-994,37)\end{array}$ & $\begin{array}{c}13,97 \pm 8,76 \\
10,86-(3,97-38,31)\end{array}$ & $\mathrm{p}>0.05$ \\
\hline
\end{tabular}

Çalışmaya alınan her iki gruptaki hastaların operasyon süresi, aorta kros klemp süresi ve pompa süreleri benzerdi $(\mathrm{p}>0.05)$.

Çalışmamızı hasta bazında süreye bağımlı olarak değerlendirdiğimizde, CRP düzeyi ve süre arasında istatistiksel olarak anlamlı veri bulunmamıştır $(p>0.05)$. Süreye bağımlı olarak IL-10 değerini incelediğimizde ise, aorta kros klemp süresindeki 1 birimlik değişim IL-10 değerini 0,175 kat arttırmakta olduğu görülmüştür $(\mathrm{p}<0.05)$. Süreye bağımlı olarak TNF- $\alpha$ düzeyi istatistiksel olarak anlamlı bulunmamıştır(p>0.05). Süreye bağımlı olarak IL-6 düzeyi değerledirildiğinde ise model istatastiksel olarak anlamlı bulunmuştur. Operasyon süresi \%10 anlamlılık düzeyindedir $(\mathrm{p}<0.001)$. Operasyon süresindeki 1 birimlik değişim IL-6’y1 0,203 kat azaltmakta olduğu bulunmuştur ( $p<0.001)$.

\section{Tartışma}

Toplumda gittikçe artan yaş ortalaması ile birlikte, kalp cerrahisi geçiren hastaların yaş ortalaması da artmaktadır. Kardiyak cerrahi esnasında kullanılan kardiyopulmoner baypas, cerrahi alanda çalışmayı kolaylaştırır ve anastomoz yapılırken oluşabilecek komplikasyonların oluşumunu en aza indirmektedir. Fakat miyokard iskemisi ve infarktüsünü engellemeye yönelik yapılan revaskülarizasyon sırasında da miyokardda iskemi ve hasar oluşabilmektedir. KPB kullanımı, TNF- $\alpha$, CRP, IL-6 gibi proinflamatuvar sitokinlerin salınımını tetikler. Bu sitokinler SIRS oluşumunu tetiklemektedir. (6) Kalp akciğer makinesindeki yabancı yüzey, pulsatil olmayan akım, anestezi ve cerrahi stres inflamatuvar reaksiyona neden olan önemli faktörlerdir.(7, 8) Ayrıca perfüzyon sicaklığının da inflamatuvar yanıtı etkileyebileceğiöne sürülmüştür.(9) KPB sırasında normotermi uygulamasına karşı, yeterli organ perfüzyonunun sağlanamaması durumunda oluşacak yan etkilerin normotermi durumunda daha az tolerans göstermesi nedeniyle, enzimatik reaksiyonların sıcaklığa bağlı olması ile genişletilmiş hücresel aktivasyona neden olabileceği ve yüksek kan akım hızlarının kan travmasına neden olabileceğinden dolayı bazı itirazlar oluşmuştur( $(10,11)$. Bu sebeple KPB esnasında uygulanabilecek antiinflamatuvar yöntemler araştırılmış ve proinflamatuvar sitokinlerin aktivasyonunu azaltmaya yönelik teknikler denenmiştir.

Bizim çalışmamızda normotermik baypas yapılan grupta IL-6, IL-10 ve CRP seviyeleri hipotermik baypas grubuna göre daha fazla yükselmiştir fakat istatistiksel olarak anlamlılık göstermemiştir.

Speziale ve arkadaşlarının (12) yapmış olduğu çalışmada 1sıya bağlı olarak IL-6 seviyelerinde anlamlı olarak yükselme olmasına reğmen TNF- $\alpha$ seviyesinde anlamlı farklılık bulunmamıştır.

Birdi ve arkadaşlarının (13) yapmış olduğu çalışmada, hipotermik KPB`nin hemostatik ve inflamatuvar sistemlerde daha derin değişikliklere yol açan, normotermik KPB`den daha büyük trombosit aktivasyonu ve endotelyal disfonksiyondan sorumludur ve bu, hipotermik KPB sirasinda bildirilen postoperatif komplikasyonlarda daha yüksek insidansa neden olduğunu göstermiştir.

Bizim çalışmamızda ise aksine inflamatuvar mediyatörlerin normotermik grupta daha fazla yükseldiği görülmüş fakat istatistiksel olarak anlamlı bulunmamıştır. Diğer bir çalışmada, normotermik baypas uygulanan hastalarda yoğun bakım kalış süresinde azalma, daha az inotrop kullanımının olduğu belirtilmiştir. $(14,15)$. Çalışmamızda operasyon süreleri arasında anlamlı farklılık bulunmamıştır.

Shibazaki ve arkadaşlarının (16) yapmış olduğu deneyse çalışmada ise normotermik KPB`nin kısa süreli ameliyatlarda, hipotermik KPB`nin ise daha uzun süreli olan ameliyatlarda kullanılması gerektiğini göstermiştir. Ayrıca ekstrakorporal devrelerin geliştirilmesi durumunda, vücut üzerinde daha az stres oluşturabileceği kanısına varmıştır. 
Sonuç olarak, KPB kullanımına bağlı sitokin salınımında birçok faktörün etkili olduğu görülmektedir. Çalışmamız yapılan diğer çalışmalarla karşılaştırıldığında benzer sonuçlar bulunmuştur. Sınırlı sayıda hasta, düşük ısı kullanılarak yapılan operasyonların az olması nedeni ile ısının inflamatuvar yanıta etkisi analiz edilse de istatistiksel olarak anlamlı bulunmamıştır. Ayrıca mali kısıtlılıklar nedeni ile sınırlı kit miktarı çalışmanın sonucunu etkilemiş olabilir. Anlamlı sonuçların alınması için daha geniş hasta grubu ve farklı ısı değerlerinde çalışmalara ihtiyaç olduğunu düşünmekteyiz. Bunun yanında hastanın klinik özellikleri, yaşı, komorbid hastalıkları, vasküler anatomi, cerrahi deneyim seçilecek yöntemde etkili olacaktır.

\section{Kaynaklar}

[1] Laffey JG, Boylan JF, Cheng DHC. The systemic inflammatory response to cardiac surgery. Anesthesiology 97; 215-52, 2002

[2] SablotzkiA, DehneMG, Mann V. Plasma levels of selectins and interleukins in cardiovascular surgery using cardiopulmonary bypass. Thorac Cardiovasc Surg 47;26-31,1999.

[3] Czerny M, Baumer H, Kilo J, Lassnigg A, Hamwi A, Vukovich T, ve ark. Inflammatory response and myocardial injury following coronary artery bypass grafting with or without cardiopulmonary bypass. Eur J Cardiothorac Surg 2000; 17: 737-42

[4] Gaudino M, Andreotti F, Zamparelli R, Di Castelnuovo A, Nasso G, Burzotta F, ve ark. The 174G/C interleukin-6 polymorphism influences postoperative interleukin-6 levels and postoperative atrial fibrillation. Is atrial fibrillation an inflammatory complication? Circulation 2003; 108: 195-9

[5] Melrose DG. A history of cardiopulmonary bypass in Taylor KM., ed. Cardiopulmonary bypass London Champman and Hall Ltd.; 1986.p1-7

[6] Caputo M, Bays S, Rogers CA, Pawade A, Parry AJ, Suleiman S, Angelini GD. Randomized comparison between normothermic and hypothermic cardiopulmonary bypass in pediatric openheart surgery. Ann Thorac Surg 2005;80:982-8

[7] Van den Goor J, Nieuwland R, van den Brink A, van Oeveren W, Rutten P, et al. Reduced complement activation during cardiopulmonary bypass does not affect the postoperative acute phase response Eur J Cardiothorac Surg 2004; 26: 926-31.

[8] Levy JH, Tanaka KA. Inflammatory response to cardiopulmonary bypass. Ann Thorac Surg 2003; 75: S715-20.

[9] Speziale G, Ferroni P, Ruvolo G, Fattouch K, Pulcinelli FM, Lenti L, et al. Effect of normothermic versus hypothermic cardiopulmonary bypass on cytokine production and platelet function. J Cardiovasc Surg (Torino) 2000; 41: 819-27.

[10] Birdi I, Caputo M, Underwood M, Bryan AJ, Angelini GD. The effects of cardiopulmonary bypass temperature on inflammatory response following cardiopulmonary bypass. Eur $\mathbf{J}$ Cardiothorac Surg 1999; 16: 540-5.

[11] Mollnes TE. Analysis of in vivo complement activation In: Weir's Handbook of Experimental Immunology. 5th ed. Boston: Blackwell Science; 1997. pp. 1-78.

[12] Speziale G, Ferroni P, Ruvolo G, Fattouch K, Pulcinelli FM, Lenti L, ve ark. Effect of normothermic versus hypothermic cardiopulmonary bypass on cytokine production and platelet function. J Cardiovasc Surg (Torino) 2000; 41: 819-27

[13] Birdi I, Caputo M, Underwood M, Bryan AJ, Angelini GD. The effects of cardiopulmonary bypass temperature on inflammatory response following cardiopulmonary bypass. Eur $\mathbf{J}$ Cardiothorac Surg 1999; 16: 540-5 
[14] Christakis GT, Koch JP, Deemar KA, Fremes SE, Sinclair L, Chen E,et al. A randomized study of the systemic effects of warm heart surgery. Ann Thorac Surg 1992; 54: 449-57.

[15] Lehot JJ, Villar J, Piriz H, Philbin DM, Carry PJ, Gauquelin G, et al. Hemodynamic and hormonal responses to hypothermic and Normothermic cardiopulmonary bypass. J Cardiothorac Vasc Anesth 1992; 11: 132-9.

[16] Shibazaki A, Matsumoto H, Shiroshita Y, ve ark.A Comparative Study between Hypothermic and Normothermic Cardiopulmonary Bypass in Open Heart Surgery in Dogs - Effects on Systemic Hemodynamics—-J. Vet. Med. Sci.1999. 61(4): 331-336. 